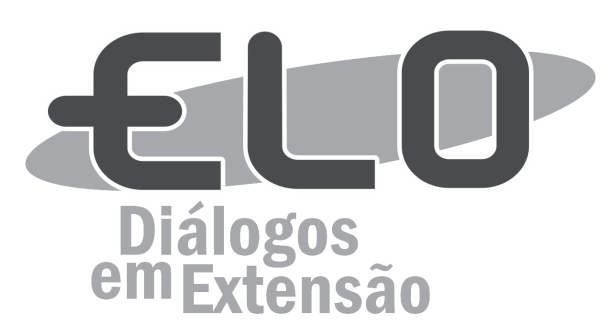

\title{
Escola Municipal Pingo de Gente: descobrindo africanidades e redescobrindo identidades
}

Lidiane Campos Villanacci ${ }^{1}$, Manuel Jauará2

\begin{abstract}
Resumo: O Programa de Extensão em História e Cultura Afro-brasileira e Africana vem, durante a sua trajetória, promovendo ações de extensão em escolas do município de São João del-Rei. Refletir sobre a concepção elementar do continente africano prevalecente, desconstruir a visão estereotipada do negro nos livros didáticoinfantis e resgatar a autoestima das crianças negras em fase de alfabetização em particular na Escola Municipal Pingo de Gente foram algumas das ações realizadas no ano de 2014. Por meio de intervenções de cunho socioeducativos, utilizando de pesquisa participante, o presente trabalho procura apresentar e discutir como $o$ projeto de extensão procurou trabalhar estudos das africanidades e relações étnico-raciais dentro de classes escolares primárias.
\end{abstract}

Palavras-chave: Intervenções psicossociais. Identidade racial. Pesquisa participante. Educação. Educação infantil.

Área Temática: Educação Infantil e relações étnico-raciais.

Municipal School "Pingo de Gente": discovering Africanities and rediscovering identities

Abstract: Throughout its trajectory, the extension program in History and Afro-Brazilian and African culture has been promoting extension actions in schools of São João del-Rei. Some actions taken in 2014: reflect about the elementary conception of the prevalent African continent; deconstruct the stereotyped view of blacks in the child textbooks; and recover the self-esteem of black children in the literacy stage, particularly in the Municipal School Pingo de Gente. By interventions socio-educative purpose, using the participant research, this work intends to present and discuss how the extension project aimed to work studies of Africanities and its racial-ethnic relations in the elementary groups from school.

Keywords: Psychosocial interventions. Racial identity. Participant research. Education. Childhood education.

\section{Escuela Municipal "Pingo de Gente": descubriendo africanidades y redescubriendo africanidades}

Resumen: El programa de extensión en Historia y Cultura Afrobrasileña y Africana ha promovido, durante su trayectoria, acciones de extensión en escuelas del municipio de São João del-Rei. Reflexionar sobre la concepción elementar del continente africano prevaleciente, desconstruir la visión estereotipada del negro en los libros didácticos infantiles y rescatar la autoestima de los niños negros en fase de alfabetización, en particular en la Escuela Municipal Pingo de Gente, fueron una de las acciones realizadas en 2014. Através de las intervenciones de carácter socioeducativos, utilizando la pesquisa participante, el presente trabajo busca presentar y discutir como el proyecto de extensión trabajó los estudios de las africanidades y relaciones étnico-raciales en grupos escolares primarios.

Palabras clave: Intervenciones psicosociales. Identidad racial. Pesquisa participante. Educación. Educación infantil.

${ }^{1}$ Graduanda em Psicologia pela Universidade Federal de São João del-Rei e bolsista do Programa em História e Cultura Afro-brasileira e Africana do Departamento de Ciências Sociais da UFSJ

${ }^{2}$ Coordenador do Programa de Extensão em História e Cultura Afro-brasileira e Africana e Professor do Departamento de Ciências Sociais da Universidade Federal de São João del-Rei 
O Programa de Extensão em História e Cultura Africana e Afro-brasileira nas escolas de São João del-Rei, sua trajetória e aplicabilidade da Lei 10.639/03

O Programa de Extensão em História e Cultura Africana e Afro-brasileira vêm desenvolvendo, ao longo dos seus quinze anos de sua existência, inúmeros trabalhos dentro das escolas municipais e estaduais da cidade de São João del-Rei, localizada em Minas Gerais. Os trabalhos são feitos através de intervenções, palestras e exposições. Para que o projeto atuasse nas escolas, durante o ano de 2014, ocorreram os encontros do grupo de estudos, tendo um de seus módulos com o tema educação e relações étnico-raciais, para que fosse possível fazer o embasamento teórico para as atividades exercidas nas escolas do município.

Segundo a lei $\mathrm{n}^{\circ} 9.394$ de 20 de dezembro de 1996, que estabelece as diretrizes e normas da educação brasileira, define o artigo primeiro:

\section{Da Educação}

Art. $1^{\circ}$. A educação abrange os processos formativos que se desenvolvem na vida familiar, na convivência humana, no trabalho, nas instituições de ensino e pesquisa, nos movimentos sociais e organizações da sociedade civil e nas manifestações culturais.

No ano de 2003, o atual governo coloca um adendo à lei de 20 de dezembro de 1996, trazendo a obrigatoriedade do ensino da história e cultura do povo negro, buscando minimizar as diferenças raciais existentes. De acordo com a lei:

\section{LEI No 10.639, DE 9 DE JANEIRO DE 2003}

Altera a Lei $n^{\circ}$ 9.394, de 20 de dezembro de 1996, que estabelece as diretrizes e bases da educação nacional, para incluir no currículo oficial da Rede de Ensino a obrigatoriedade da temática "História e Cultura Afro-Brasileira", e dá outras providências.

Ao completar quatorze anos da lei 10.639/03 e treze anos do parecer CNE/CP 003/2004, que institui as Diretrizes Curriculares Nacionais para a Educação das Relações Étnico-raciais e para o Ensino de História e Cultura Afro-brasileira e Africana no currículo escolar, o desafio ainda está na possibilidade de desmistificar algumas representações em relação à história africana e afro-brasileira. Segundo as diretrizes supracitadas:

Garantir o exercício desse direito e forjar um novo modo de desenvolvimento com inclusão é um desafio que impôs ao campo da educação decisões inovadoras. Na reestruturação do MEC, o fortalecimento de políticas e a criação de instrumentos de gestão para a afirmação cidadã tornaram-se prioridades, valorizando a riqueza de nossa diversidade étnico-racial e cultural.

No campo da educação básica, estudos recentes corroboram a urgência na reelaboração da formação acadêmica e currículo escolar, uma vez que estes não estão aptos a reconhecer e combater atitudes transmissoras de preconceitos nas suas próprias atitudes como em todo contexto escolar. Essa afirmação pode ser constatada pela pesquisadora Vilma Baia Coelho em entrevista ao Jornal do Estado de Minas, em dezesseis de setembro de 2006, quando relata ter observado vários professores justificando a ausência de crianças negras na escolha dos que devem representar a escola pelo motivo de boa aparência e pela timidez das crianças negras.

Para que possa ocorrer uma mudança, pelo menos nas escolas atendidas pelo projeto, o Programa de Extensão em História e Cultura Africana e Afro-brasileira atua para que se possibilite haver uma capacitação dos profissionais atuantes e em formação para agir no espaço escolar, com a finalidade de promover a implementação da lei e por consequência apresentar a esses profissionais; tanto em atuação como em formação; a história do povo negro no Brasil, sua origem e sua representatividade social. Uma dessas ações é o Curso de Extensão e Aperfeiçoamento em História e Cultura Afro-brasileira e Africana.

Trazer para a discussão, em ambiente acadêmico, a questão da representatividade do negro tornase significativo uma vez que há um número exacerbado de teorias e fenômenos transmitidos socialmente e que não podem ser corroborados individualmente (MOSCOVICI, 2003). Suscitando essa ideia, Silva (2002) afirma que em relação a representatividade social do negro existe uma percepção quase coletiva 
socialmente que o transforma em algo estigmatizado, fora do convívio familiar e estranho. A representação pode ser considerada como meio de produção, uma vez que esta passa a ser processo de identificação, em outras palavras, a representação faz parte de um processo identitário do sujeito (CIAMPA, 1984). A partir desses pressupostos o programa de extensão em discussão, procurou reconhecer essa preconcepção e ressignificá-la em suas atuações na comunidade interna externa da Universidade Federal de São João del-Rei.

Refletindo sobre esses conceitos e através da atuação do Programa/Projeto, pôde-se conceber que somente a legislação não trouxe mudanças necessárias no âmbito escolar. Mesmo após quatorze anos de vigor da lei 10.639/03 ainda é insatisfatório o ensino da história e cultura africana e afro-brasileira nas escolas, sendo muitas vezes praticado de forma estereotipada, pouco aprofundada e geralmente apenas desenvolvida em datas comemorativas, como por exemplo, o dia da Consciência Negra. Dessa forma é necessário que universidade, escola e comunidade atuem de maneira conjunta para que os estudos sobre as africanidades, combate ao preconceito racial e a descolonização do currículo escolar (GOMES, 2012) ocorram dentro do espaço da escola.

\section{Primeiros contatos com africanidades e constituindo identidades na Educação Infantil}

Uma das bases da existência do Programa de Extensão em História e Cultura Afro-brasileira e Africana é a efetivação da lei 10639/03 nas escolas da cidade de São João del-Rei. Para que isso possa ocorrer, as ações da extensão localizam-se sumariamente nas escolas da cidade e região. Uma das escolas atendidas pelo projeto no ano de 2014 foi a Escola Municipal Pingo de Gente.

A escolha da escola se dá pela quantidade significativa de crianças negras e para a atuação do projeto também na educação infantil. Os primeiros anos educacionais, obrigatórios para crianças a partir dos quatro anos de idade, torna-se o primeiro espaço no qual os alunos interagem e trocam experiências fora do contexto familiar, formando-se assim um espaço onde pôde-se perceber os reflexos inseridos nestas crianças de um contexto social extraescolar e familiar.

Tornam-se os princípios de atuação do projeto nas escolas detectar a presença ou não de métodos de transmissão ou reprodução do preconceito racial (Fazzi, 2004) nas relações entre alunos e educadores, desconstruir a imagem do negro estereotipada nos livros didáticos e resgatar a autoestima das crianças negras, utilizando-se da efetivação da lei 10639/03. Construir uma pedagogia plural, que priorize o trato não discriminador das diferenças valorizando-as e respeitando-as, não as colocando em um campo de conflitos e desigualdades; e incentivar e difundir as formas de educação que estimulem a convivência na diversidade étnica e cultural tornaram-se os principais objetivos da intervenção e pesquisa do Programa de Extensão em História e Cultura Afro-brasileira e Africana.

\section{Construindo um espaço escolar que possibilite o processo identitário da criança perpassar o campo da reflexão multicultural social}

Para Dessen e Polonia (2007) a escola é um espaço de contexto diversificado nos campos de desenvolvimento e aprendizagem, ou seja, é um ambiente que engloba diversidades de conhecimentos, regras e valores, rodeados por conflitos, problemas e diferenças. A escola também é um espaço de ordem física, psicológica, social e cultural onde os indivíduos nele inserido podem processar seu desenvolvimento global através das atividades propostas dentro e fora de sala de aula. As autoras ainda afirmam que a escola é um ambiente multicultural que abrange a construção de laços afetivos e prepara para a inserção do individuo na sociedade.

Nesse entendimento, o Programa de Extensão em História e Cultura Africana e Afro-brasileira procura intervir dentro das instituições de ensino estaduais e municipais da cidade de São João delRei, localizada no campo das vertentes no estado de Minas Gerais, promovendo debates, discussões e exposições acerca da temática do projeto ao longo de sua existência. No ano de 2014 foram realizadas oficinas, exposições nas escolas da cidade e palestra-debate na modalidade de Educação de Jovens e Adultos (EJA), dando continuidade nos trabalhos realizados pelo projeto nos anos anteriores.

Na Escola Municipal Pingo de Gente, as oficinas ocorreram durante todo o ano de 2014 envolvendo crianças de três a quatro anos. O projeto atendeu quatro turmas do período vespertino, totalizando setenta e duas crianças. Neste período, considerado como educação infantil, é necessário existir uma 
atenção especial aos tipos de afeto que a criança recebe e como ela significa essas relações estabelecidas, afirma Santana (2010). Ainda segundo a autora

é com o outro, pelos gestos, pelas palavras, pelos toques e olhares que a criança construirá sua identidade e será capaz de reapresentar o mundo atribuindo significados a tudo que a cerca. Seus conceitos e valores sobre a vida, o belo, o bom, o mau, o feio entre outras coisas, começam a se constituir nesse período.

Dessa forma é necessário pensar criticamente como os educadores mantém suas relações com as crianças. A partir dessa premissa, a bolsista responsável pelas intervenções em um primeiro momento fez um trabalho de observação do ambiente escolar, onde as oficinas aconteceriam. Para esta observação foi feito um estudo sistemático sobre o preconceito racial na infância, levantando inicialmente possíveis mecanismos de aquisição de atitudes raciais, focando principalmente no ambiente escolar. Fazzi (2004) afirma que embora os mecanismos de transmissão de atitudes raciais sejam semelhantes para todas as crianças, o ambiente sociológico, psicológico e o pertencimento racial podem afetar a intensidade dos sentimentos e as reações a eles. Desse modo, podemos concluir que a transmissão de preconceito não é automática e que possam existir crianças mais ou menos preconceituosas e crianças mais sensíveis ao preconceito dentro do espaço de contexto escolar.

Após o trabalho de observação, iniciaram-se as primeiras intervenções com as crianças. No primeiro contato com os alunos, a oficina ocorreu através de uma dinâmica para que se estabelecesse inicialmente uma boa relação com estes. A partir da criação de vínculo entre a bolsista e as crianças, as intervenções voltaram-se para os primeiros contatos destas com a história e cultura africana e afro-brasileira. Foram utilizados vídeos, desenhos, histórias, dinâmicas, brincadeiras entre outros recursos para introduzir as crianças aos primeiros estudos das africanidades. Em um segundo momento, as intervenções voltaram-se para uma tentativa de combate ao preconceito de toda natureza dentro do ambiente escolar e resgate da autoestima dos alunos negros, maioria na escola onde ocorreram as oficinas. Para esta parte do trabalho, foram utilizadas imagens e estórias em que as crianças se identificassem com os personagens e criassem uma visão positiva da imagem do negro.

Para a elaboração das intervenções foi necessário recorrer as bases da pesquisa participante e da pesquisa-ação (THIOLLENT, 1984) assim como as oficinas de grupo (AFONSO, 2000). Segundo a teoria utilizada, o interventor/pesquisador deve estar ciente da realidade e do contexto em que o grupo envolvido está inserido, procurando se aproximar do contexto social dos indivíduos pertencentes ao grupo com a finalidade de que o interventor possa criar um vínculo com estes para apreender as demandas advindas dos sujeitos inseridos no grupo e no contexto histórico que este pertence. Entender o contexto social do individuo ou grupo que este se encontra torna-se fundamental uma vez que não se pode dissociar o processo identitário do mesmo com o da sociedade, em suma, as possibilidades de diferentes constituições de identidades estão diretamente ligadas às diferentes constituições de ordem social (CIAMPA, 1984). Identidade pode ser intendida também por Hall (2006)como:

Assim, a identidade é realmente algo formado, ao longo do tempo, através de processos inconscientes, e não algo inato, existente na consciência no momento do nascimento. Existe sempre algo "imaginário" ou fantasiado sobre sua unidade. Ela permanece sempre incompleta, está sempre incompleta, está sempre "em processo", sempre "sendo formada".

Desse modo, por meio da pesquisa participante, foi possível a criação de vínculo entre a bolsista do projeto e as crianças do primeiro ano de alfabetização da escola Municipal Pingo de Gente. A partir do contato inicial com as crianças foi possível diagnosticar e trabalhar as demandas do grupo, criar intervenções estruturadas com a finalidade de provocar um pensamento crítico-reflexivo e a partir dos resultados obtidos propiciar continuidade ao trabalho proposto.

\section{Detectando os fatores de transmissão de preconceitos em sala de aula e introduzindo os primeiros contatos com as africanidades}

O trabalho de observação, inicialmente realizado pela bolsista, pôde esclarecer aspectos da educação infantil, conhecer o projeto pedagógico da escola, observar o desenvolvimento físico, cognitivo e 
psicossocial das crianças na faixa etária de três a quatro anos, levantar demandas e propiciar a criação de vínculo entre a interventora/pesquisadora e as quatro classes do primeiro ano de alfabetização da escola supracitada. Pôde-se também, para fins de pesquisa e coleta e dados, a observação do corpo profissional da escola, para constatar se estes configuravam-se omissos ou não quanto à temática racial; se havia uma politica que valorizasse o multiculturalismo presente em sala de aula, o conhecimento dos professores em relação a lei 10.639/03, qual a concepção dos educadores sobre a ideologia do embranquecimento e a observar a incidência de atitudes e discursos discriminadores dentro de sala de aula.

Neste primeiro momento levantaram-se as demandas a cerca do conhecimento sobre o continente africano das crianças, com a finalidade de melhor apresentar a história e cultura africanas. Após a constatação de que as crianças tinham uma visão fantasiosa sobre o continente ou que imaginavam haver somente animais no continente, foi preciso fazer uma desconstrução sobre a imagem irreal que as crianças tinham concebido. Por meio de intervenções estruturadas, jogos, dinâmicas e utilizando-se de recurso audiovisuais as crianças puderam reconstruir uma imagem do continente africano sem os elementos fantasiosos e não somente com as figuras de animais. Foram apresentadas às estas crianças a concepção real do continente africano de forma lúdica, possibilitando uma reconstrução no imaginário destas de algo próximo a uma realidade existente, desconstruindo a imagem, muitas vezes estereotipada do continente africano.

A ressonância da primeira etapa das intervenções mostra-se em uma reelaboração do imaginário das crianças ao serem questionadas segundo momento sobre o que elas imaginavam ser o continente africano. Ao serem questionadas pela primeira vez sobre o que seria a África, obteve-se respostas como "um lugar longe onde tem fantasmas" ou "onde tem leão, elefante, girafa". Após as intervenções iniciais, as crianças relataram, ao serem questionadas novamente, que a África seria como qualquer outro lugar em que havia pessoas, prédios, árvores e carros, trazendo esse imaginário a uma realidade próxima ao que corresponde ao continente africano de fato.

Além de possibilitar uma reconstrução do conceito sobre o continente africano para as crianças nesta primeira etapa do trabalho, observou-se também a relação destas com as professoras e entre seus pares. Pôde-se constatar que haveria certo desconhecimento sobre o continente africano das professoras, quando duas destas se referiram a ele como um país. Outra constatação feita refere-se ao que Fazzi (2004) afirma em relação ao fator transmissor e reprodutor de preconceito racial entre alunos e professores. Através das brincadeiras, livros didáticos, relações entre alunos e professores pôde-se levantar aspectos reprodutores de discriminação racial como apelidos e preferências dos professores pelos alunos brancos aos negros, o que sugere a intensificação da educação continuada para temática para educadores, salvo algumas exceções.

Nas observações feitas pela bolsista os fatores transmissores de preconceito racial dentro de sala de aula, citados por Fazzi (2004), se tornaram claramente perceptíveis. Em uma escola, com classes de aula em quase sua totalidade compreendida por crianças negras, foi constatado o uso do conceito de beleza eurocentrista, com a imagem de crianças brancas e loiras, para a confecção de cartões para identificação com os nomes das crianças, o que exemplifica o próprio despreparo da professora ao representar meninos e meninas negras com um estereotipo que não os representa.

O despreparo das professoras, em relação a questão identitária e o representacionismo dentro de sala de aula, ainda pôde ser observado em uma sala de aula com dezoito alunos, sendo dezessete de origem negra e apenas um branco, na preferência da professora pelo aluno de pele mais clara ao ser pego diversas vezes no colo pela professora e tendo seus cabelos sendo acariciados pela professora dizendo o quanto "são lindos". Perceber e refletir sobre as atitudes do corpo docente frente aos problemas relacionados aos mecanismos de transmissão de preconceito racial traz a esse trabalho o intuito de levantar a discussão acadêmica em torno da formação de educadores preparados a pensar e criticar atitudes preconceituosas e exclusivas.

\section{Descobrindo identidades e resgatando a autoestima do aluno negro}

A segunda etapa das intervenções consistiu em desfazer os estereótipos a cerca do negro construído por uma sociedade colonizadora, reelaborar novos padrões de beleza e resgatar a autoestima da criança negra. Nessa etapa foram elaboradas intervenções estruturadas baseadas em histórias, contos, jogos e dinâmicas em que a visão sobre o negro fosse positivada, ao contrário de alguns livros didáticos em 
que o negro é representado de forma estereotipada e caricatural (SILVA, 2008). A estereotipia do negro é definida por Sant'Ana como sendo a prática do preconceito e sendo manifestada pelo comportamental, segundo o autor "o estereótipo objetiva justificar uma suposta inferioridade; justificar a manutenção do status quo; e legitimar, aceitar e justificar: a dependência, a subordinação e a desigualdade" (SANT'ANA, 2008,p.35).

Os resultados da segunda etapa do trabalho realizado junto à Escola Municipal Pingo de Gente resultaram na reconstrução positiva da imagem do negro das crianças envolvidas, nos processos de construção da autoestima dos alunos negros e na reelaboração dos conceitos ligados à negritude pelas professoras da escola. Pode-se observar, após uma das intervenções em que foi apresentada a estória de Ana Maria Machado "Menina Bonita Laço de Fita", onde a personagem principal da estória aprende a sua origem. a valorizar a sua cor e os seus cabelos anelados. A história pôde proporcionar as crianças negras entenderem a importância de valorizar a sua cor e promoveu expressões de orgulho dos cabelos anelados das meninas.

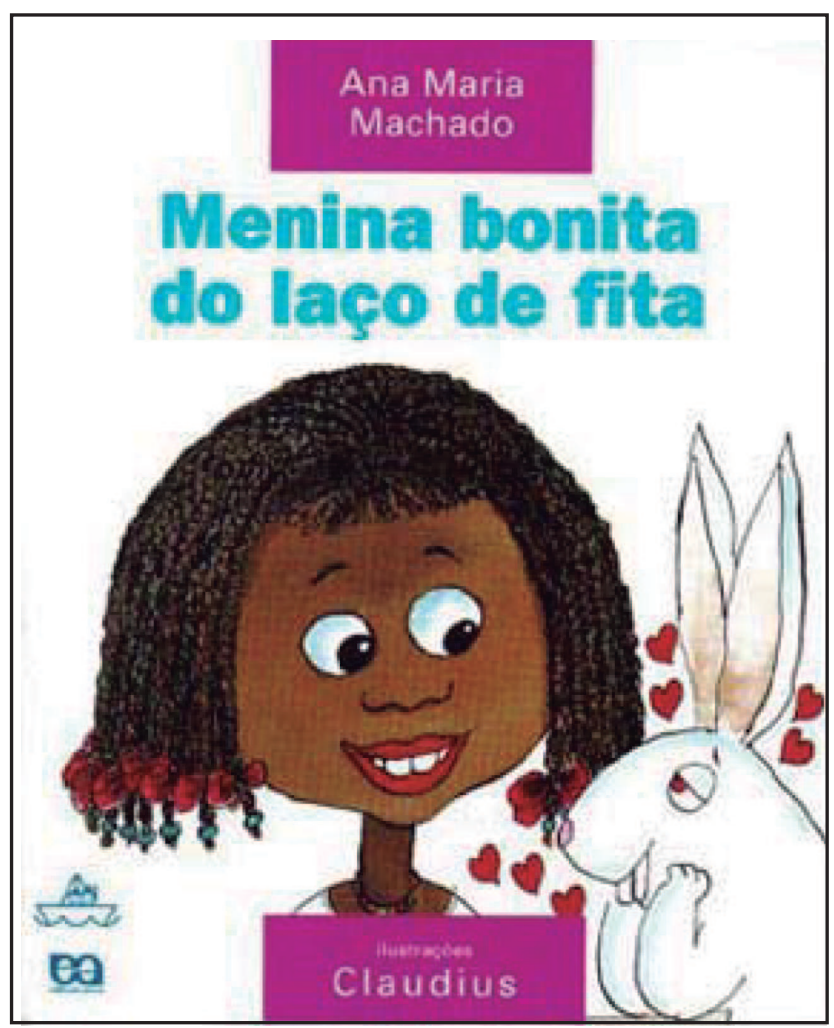

Figura 1 - Livro de Ana Maria Machado, Menina Bonita Laço de Fita Fonte: Machado. Ana Maria: Menina bonita do laço de fita. $7^{\circ}$ edição. São Paulo. Ártica, 2005.

A questão da identidade e representatividade nas estórias infantis também foi marcante na leitura do livro "Os cabelos de Lelê" de autora Valéria Belém, onde a personagem principal encontra sua ancestralidade e identidade em um livro onde são apresentados os mais diversos tipos de cabelo afros.

Depois do Atlântico, a África chama

E conta uma trama de sonhos e medos

De guerras e vidas e mortes no enredo

Também de amor no enrolado cabelo

Puxado, armado, crescido, enfeitado

Torcido, virado, batido, rodado

São tantos cabelos, tão lindos, tão belos!

(Belém, 2012) 


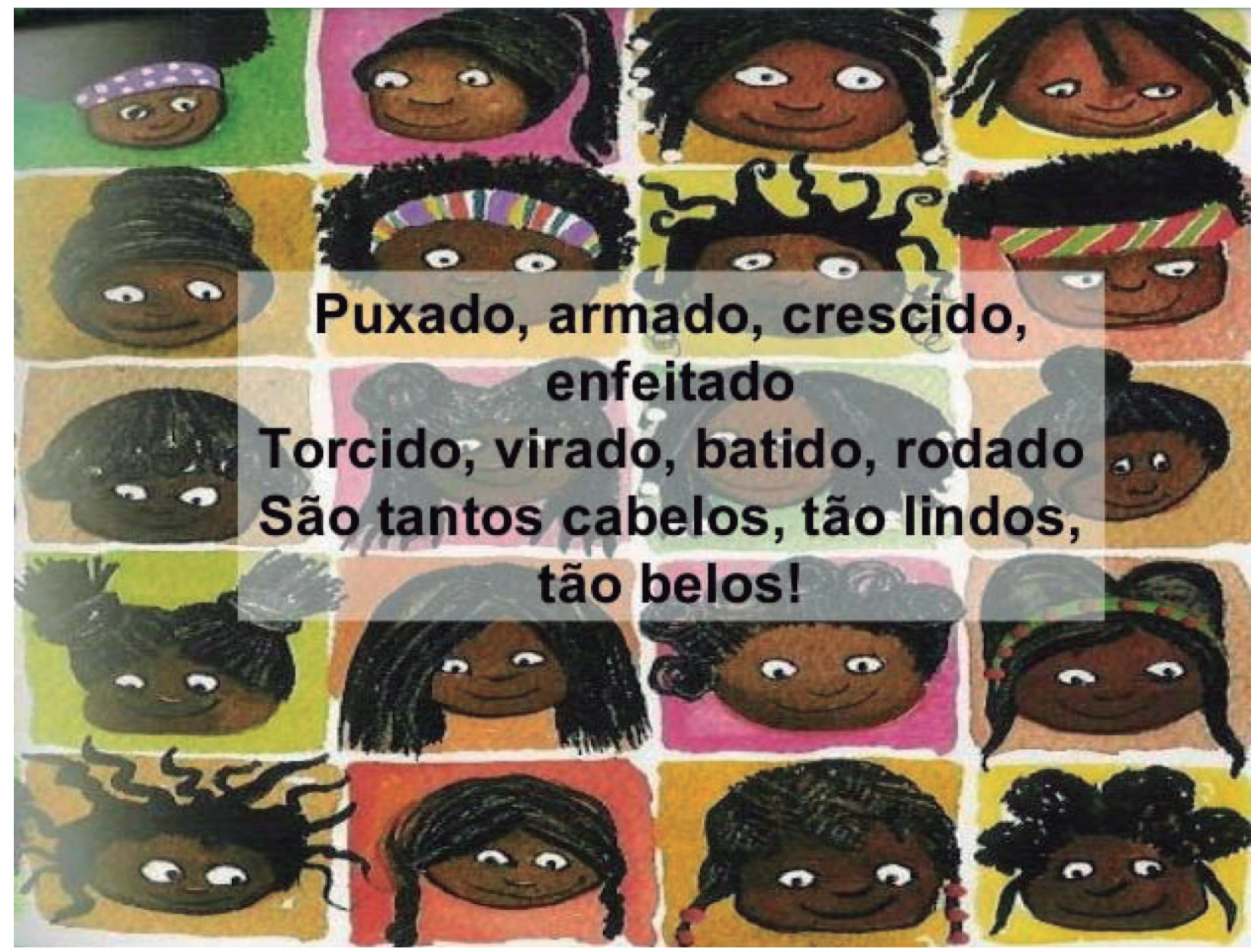

Figura 2 - Os diversos tipos de cabelos encontrados no continente africano, apresentados no livro Os cabelos de Lelê de autoria de Valéria de Belém

Fonte: BELÉM, Valéria. O cabelo de Lelê. 2d. São Paulo: IBEP, 2012.

\section{CONCLUSÃO}

O projeto em análise desenvolvido no ano de 2014 em parceria com várias escolas do município de São João del-Rei, procurou suscitar uma nova reflexão acerca dos conceitos preconcebidos do continente africano, estimular uma nova visão sobre o negro e resgatar a autoestima dos alunos negros do primeiro ano de alfabetização que envolveu setenta e duas crianças e quatro professores. $\mathrm{O}$ projeto procurou proporcionar a essas crianças o fortalecimento de uma convivência na qual os estereótipos possam ser corrigidos e todos os grupos possam viver com um menor impacto do preconceito racial.

Para que seja aplicado com sucesso a Lei 10639/03 torna-se necessário que as instituições de ensino, visando a reparações, reconhecendo e valorizando a identidade, cultura e trajetória social dos grupos negros, ofereçam condições de ensino e aprendizagem favoráveis, ou seja, que alunos negros e não-negros sintam-se acolhidos e apoiados. É fundamental ainda que ocorra um trabalho em comum, articulando-se processos educativos e escolares, politicas públicas, engajamentos sociais entre outros, uma vez que mudanças comportamentais, éticas, pedagógicas, cultural e social não se limitam ao campo escolar (BRASIL, 2004)

Entendemos que o projeto em si não é suficiente para reelaborar conceitos e identidades das crianças brancas e negras e levarem os alunos negros a reconhecerem-se como seres diferentes, com histórias diferentes, nem superiores nem inferiores (ANDRADE, 2008), mas pode ser o início de um processo que possa fomentar a incrementação de uma nova concepção da educação étnico-racial. Mas ainda há ainda muito o que fazer em relação a educação étnico raciais, espera-se que os demais projetos na área de educação convertam seus esforços no sentido de criar um imaginário social coletivo com menos preconceito, sobretudo no espaço escolar. 


\section{Fonte de Financiamento}

Pró-Reitoria de Extensão e Assuntos Comunitários da Universidade Federal de São João del-Rei

\section{Agradecimentos}

Agradecemos a Pró-Reitoria de Extensão e Assuntos Comunitários da Universidade Federal de São João del-Rei pelo apoio financeiro ao Projeto/Programa. À Escola Municipal Pingo de Gente pela calorosa acolhida à bolsista da equipe, em especial ao corpo docente da escola assim como a colaboração das famílias das crianças envolvidas. Não podemos deixar de agradecer também a toda equipe Tuguná pelo apoio e troca de experiências e ao nosso orientador, Professor Dr. Manuel Jauará.

\section{Referências}

AFONSO, Lúcia (Org.). Oficinas em dinâmica de grupo: um método de intervenção psicossocial. Belo Horizonte: Edições do Campo Social, 2000.

ANDRADE, I. P. Construindo a auto-estima da criança negra. In: MUNAGA, Kabengele. Superando o racismo na escola. Brasília: Ministério da Educação, Secretaria de Educação Continuada, Alfabetização e Diversidade, 2008.

BRASIL. Constituição (1988). Constituição da República Federativa do Brasil. Brasília, DF: Senado Federal: Centro Gráfico, 1988.

BRASIL. Ministério da Educação/Secad. Diretrizes curriculares nacionais para a educação das relações étnico-raciais e para o ensino de história e cultura afro-brasileira e africana na educação básica. 2004.

BRASIL. Lei 9394 - 24 de dezembro de 1996. Lei de diretrizes e bases da educação nacional. Brasília: Ministério da Educação, 1996

BELÉM, Valéria. O cabelo de Lelê. 2d. São Paulo: IBEP, 2012.

CIAMPA, Antonio da Costa. Identidade. In: W. Codo \& S. T. M Lane (Orgs.). Psicologia social: o homem em movimento (pp. 58-75), São Paulo: Brasiliense, 1984.

DESSEN, M. A., POLONIA A.C. A família e a escola como contextos de desenvolvimento humano. Paidéia. Brasília, Distrito Federal, 2007. Disponível em: <http://www.scielo.br/pdf/paideia/v17n36/ v17n36a03.pdf>. Acesso em: 18 ago. 2015.

FAZZI, R. de C. O drama racial das crianças brasileiras: socialização entre pares e preconceito. Belo Horizonte: Autêntica, 2006.

GOMES, N. L. Relação étnico-raciais, educação e descolonização dos currículos. Disponível em: <http:// www.acaoeducativa.org>. Acesso em: 20 ago. 2015.

HALL, Stuart. A identidade cultural na pós-modernidade. Tradução Tomaz Tadeu da Silva e Guacira Lopes Louro. 11ed. Rio de Janeiro: DP\&A, 2006.

MOSCOVICI, Serge. Por que estudar representações sociais em psicologia? Estudos Goiânia. S/n, v. 30, n. 1, p. 11-30, jan/2003

SANTANA, P. M. S. Educação Infantil. In: Ministério da Educação, Secretaria de Educação Continuada, Alfabetização e Diversidade. Orientações e ações para a educação das relações étnico-raciais. Brasília: SECAD, 2010

SANT'ANA, O. História e conceitos básicos sobre o racismo e seus derivados. In: MUNAGA, Kabengele. Superando o racismo na escola. Brasília: Ministério da Educação, Secretaria de Educação Continuada, Alfabetização e Diversidade, 2008.

SILVA, Ana Célia da. A representação social do negro no livro didático: o que mudou? 25 Reunião anual da ANPED. Caxambu, V.1, p. 1- 123, 2002. 
SILVA, A. C. A desconstrução da discriminação no Livro Didático. In: MUNAGA, Kabengele. Superando o racismo na escola. Brasília: Ministério da Educação, Secretaria de Educação Continuada, Alfabetização e Diversidade, 2008.

Machado. Ana Maria: Menina bonita do laço de fita. $7^{\circ}$ edição. São Paulo. Ártica, 2005.

THIOLLENT, M. Notas sobre o debate pesquisa-ação. In: BRANDÃO, Carlos Rodrigues. Repensando a pesquisa participante. São Paulo: Brasiliense, 1984.

Recebido para publicação em 10/10/2016 e aprovado em 10/3/2017. 